This document is confidential and is proprietary to the American Chemical Society and its authors. Do not copy or disclose without written permission. If you have received this item in error, notify the sender and delete all copies.

\title{
Artificial Metalloenzymes Based on the Biotin-Streptavidin Technology: Challenges and Opportunities
}

\begin{tabular}{|r|l|}
\hline Journal: & Accounts of Chemical Research \\
\hline Manuscript ID & ar-2016-00235u.R1 \\
\hline Manuscript Type: & Article \\
\hline Date Submitted by the Author: & 27-Jul-2016 \\
\hline Complete List of Authors: & $\begin{array}{l}\text { Heinisch, Tillmann; University Basel, Chemistry } \\
\text { Ward, Thomas; University of Basel, Department of Chemistry }\end{array}$ \\
\hline
\end{tabular}

\section{SCHOLARONE ${ }^{\text {Tw }}$ \\ Manuscripts}




\title{
Artificial Metalloenzymes Based on the Biotin-Streptavidin Technology:
} Challenges and Opportunities

\author{
Tillmann Heinisch and Thomas R. Ward* \\ Department of Chemistry, University of Basel, Spitalstrasse 51, CH-4056 Basel, Switzerland \\ email: thomas.ward@unibas.ch
}

\section{Conspectus}

The biotin-streptavidin technology offers an attractive means to engineer artificial metalloenzymes (ArMs). Initiated over fifty years ago by Bayer and Wilchek, the biotin-(strept)avidin techonology relies on the exquisite supramolecular affinity of either avidin or streptavidin for biotin. This versatile tool, commonly refered to as "molecular velcro", allows to nearly irreversibly anchor biotinylated probes within a (strept)avidin host protein. Building upon a visionary publication by Whitesides from 1978, several groups have been exploiting this technology to create artificial metalloenzymes. For this purpose, a biotinylated organometallic catalyst is introduced within (strept)avidin to afford a hybrid catalyst that combines features reminiscent of both enzymes and of organometallic catalysts. Importantly, ArMs can be optimized by chemo-genetic means. Combining a small collection of biotinylated organometallic catalysts with streptavidin mutants allows to generate significant diversity, thus allowing to optimize the catalytic performance of ArMs. Pursuing this strategy, the following reactions have been implemented: hydrogenation, alcohol oxidation, sulfoxidation, dihydroxylation, allylic alkylation, transfer hydrogenation, Suzuki cross-coupling, C-H activation, metathesis. In this account, we summarize our efforts in the latter four reactions. X-ray analysis of various ArMs based on the biotin-streptavidin technology reveals the versatility and commensurability of the biotinbinding vestibule to accomodate and interact with transition states of the scrutinized organometallic transformations. In particular, streptavidin residues at positions 112 and 121 recurrently lie in the close proximity of the biotinylated metal cofactor. This observation led us to develop a streamlined 24-well plate streptavidin production and screening platform to optimize the performance of ArMs.

To date, most of the efforts in the field of ArMs have focused on the use of purified protein samples. This seriously limits the throughput of the optimization process. With the ultimate goal of complementing natural enzymes in the context of synthetic- and chemical biology, we outline the milestones required to ultimately implement ArMs within a cellular enviroment. Indeed, we believe that ArMs may allow to signficantly expand the natural enzymes' toolbox to access new-to-nature reactivites in vivo. With this ambitious goal in mind, we report on our efforts to i) activate the biotinylated catalyst precursor upon incorporation within Sav, ii) minimize the effect of the cellular 
environment on the ArM's performance and iv) demonstrate the compatibility of ArMs with natural enzymes in cascade reactions.

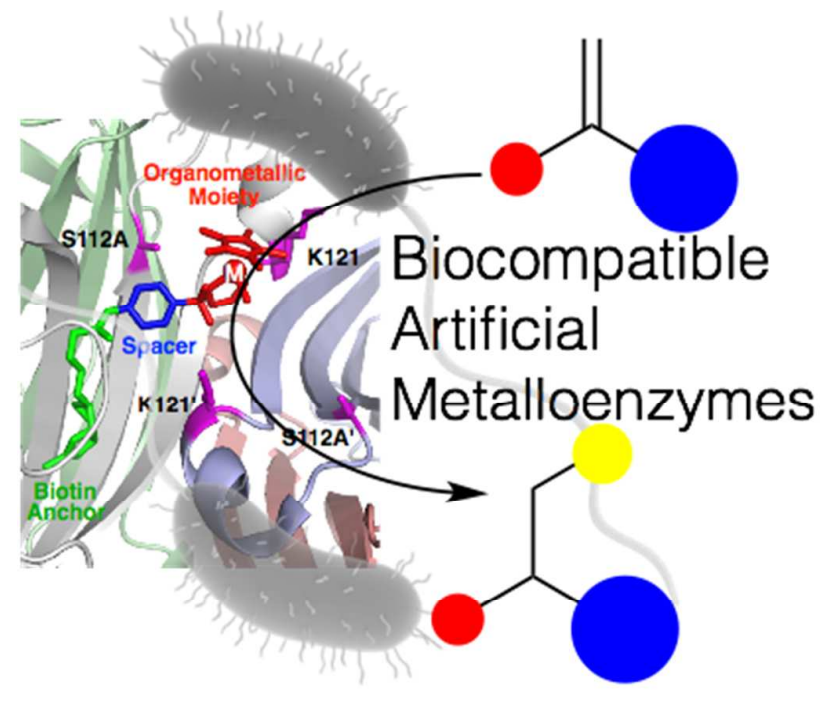

\section{Imine reduction metathesis C-H activation enzyme cascades catalysis in cell lysates}

\section{Introduction}

Traditionally, catalysis has been divided into three subdisciplines: heterogeneous-, homogeneous- and enzymatic catalysis. In recent years, artificial metalloenzymes (ArMs) have emerged as an attractive alternative to complement these. ArMs result from anchoring a metal cofactor within a host protein, thereby combining features of both homogeneous catalysts and enzymes. Three strategies have been pursued for the creation of ArMs: i) repurposing natural metalloenzymes for abiotic transformation, ${ }^{1-4}$ ii) in silico metalloenzyme (re-)design, ${ }^{5-8}$ and iii) incorporation of abiotic cofactors into proteins. ${ }^{9-16}$

Inspired by Whitesides, we and others have exploited the biotin-(strept)avidin technology to localize a biotinylated metal cofactor within (strept)avidin. ${ }^{17-20}$ Optimization of the performance of the resulting ArMs is best achieved relying on chemo-genetic means: combining a collection of biotinylated organometallic cofactors with a library of streptavidin mutants (Sav hereafter), Scheme 1. Relying on this strategy, ArMs based on the biotin-streptavidin technology have been developed for: hydrogenation, ${ }^{21,22}$ allylic alkylation, ${ }^{23}$ dihydroxylation, ${ }^{24}$ sulfoxidation, ${ }^{25}$ alcohol oxidation, ${ }^{26}$ transfer hydrogenation of ketones, ${ }^{27,28}$ enones $^{29}$ and imines, ${ }^{30-36}$ Suzuki cross-coupling, ${ }^{37} \mathrm{C}-\mathrm{H}$ activation, ${ }^{38}$ and

olefin metathesis. ${ }^{39,40}$ Whereas our initial focus, summarized in $2011,{ }^{10}$ relied on screening using purified Sav samples, we outline herein our efforts to adapt this technology to complement natural 
enzymes in a cellular environment. This ambitious goal was fueled by the tenet that ArMs may be used to complement natural enzymes in synthetic biology.

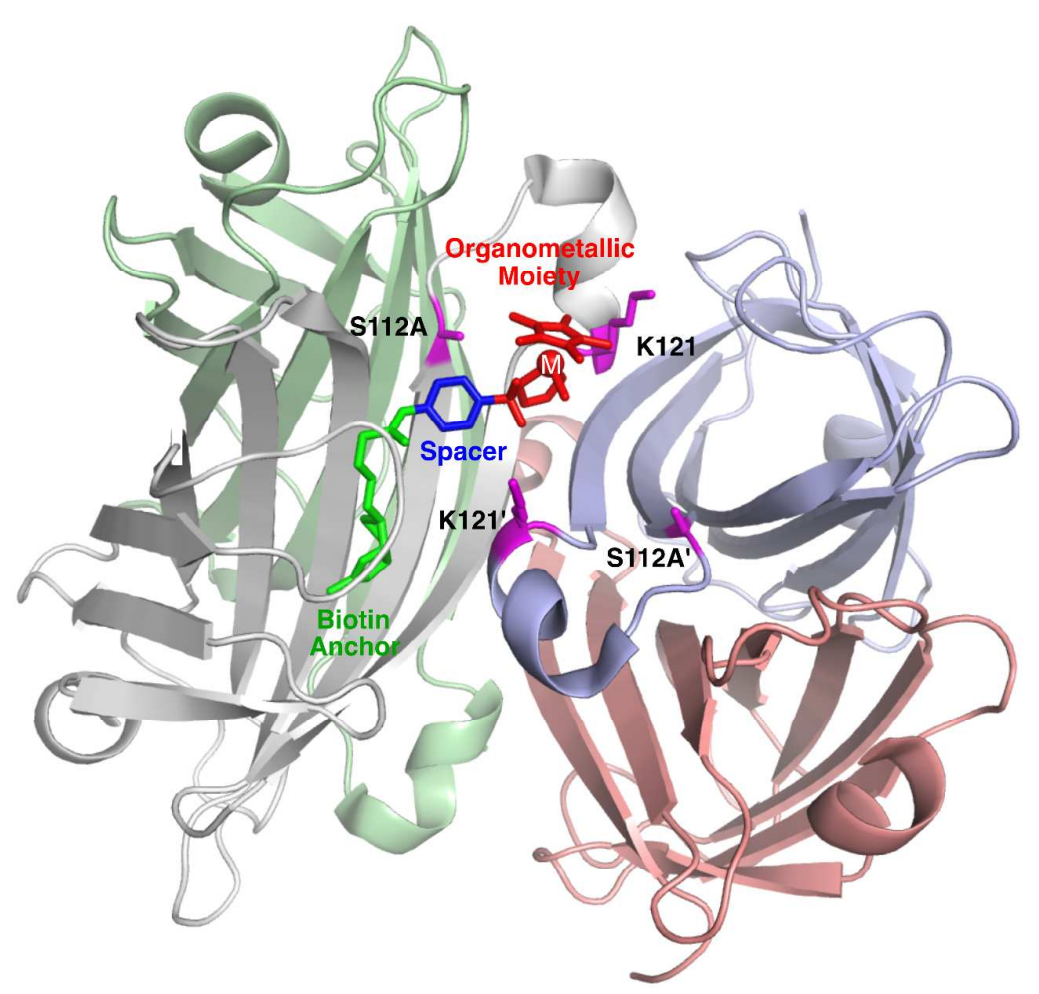

Scheme 1. Chemogenetic optimization of artificial metalloenzymes based on the biotin-stretpavidin technology. Variation of the spacer (blue) between the biotin anchor (green) and the organometallic moiety (red) combined with streptavidin mutants (magenta) allows to optimize the performance of ArMs.

To address this challenge, we identified the following milestones: i) develop ArMs for reactions absent from the natural enzyme's repertoire, ii) activate the biotinylated catalyst precursor upon incorporation within Sav, iii) minimize the effect of the cellular environment on the ArM's performance and iv) demonstrate the compatibility of ArMs with natural enzymes. 


\section{New-to-nature reactions catalyzed by ArMs}

\subsection{Transfer hydrogenation of imines and enones}

Homogeneous asymmetric transfer-hydrogenation was pioneered in the early 1990s by Noyori. For this purpose, $\mathrm{d}^{6}$-pianostool complexes bearing an enantiopure 1,2-aminosulfonamide ligand proved most efficient. ${ }^{41}$ Transfer-hydrogenation is a mild alternative to hydrogenation, which catalyzes the $\mathrm{H}_{2}$-transfer from an organic donor, typically formate or isopropanol, to a prochiral ketone, imine or enone substrate. Despite the abundance of natural keto-reductases, no imine reductase had been reported prior to $2011 .^{42}$ Having demonstrated the versatility of the biotin-streptavidin technology for artificial keto-reductases, ${ }^{27,28}$ we set out to adapt the system for the reduction of imines and activated alkenes.

Tethering a biotin-anchor to an aminosulfonamide ligand (Biot- $p-\mathrm{L}^{1}$ hereafter) allows to localize a pianostool within Sav. While for the artificial keto-reductase, $\left[\left(\eta^{6}\right.\right.$-arene)Ru(Biot- $\left.\left.p-\mathrm{L}^{1}\right) \mathrm{Cl}\right]$-proved most efficient, ${ }^{27,28}$ the iridium analog $\left[\left(\eta^{5}-\mathrm{Cp} *\right) \operatorname{Ir}\left(\right.\right.$ Biot- $\left.\left.p-\mathrm{L}^{1}\right) \mathrm{Cl}\right]\left(\mathrm{Cp}^{*}=\mathrm{C}_{5} \mathrm{Me}_{5}\right)$ clearly outperformed the Ru-complex for the reduction of imines. Initial experiments using $\left[\left(\eta^{5}-\mathrm{Cp} *\right) \operatorname{Ir}\left(\right.\right.$ Biot- $p$ - $\left.\left.\mathrm{L}^{1}\right) \mathrm{Cl}\right] \mathbf{C} \mathbf{1}$. WT Sav afforded $(R)$-salsolidine $\mathbf{1}$ from the cyclic imine $\mathbf{2}$ in $57 \%$ ee, Scheme $2 .^{30}$ 


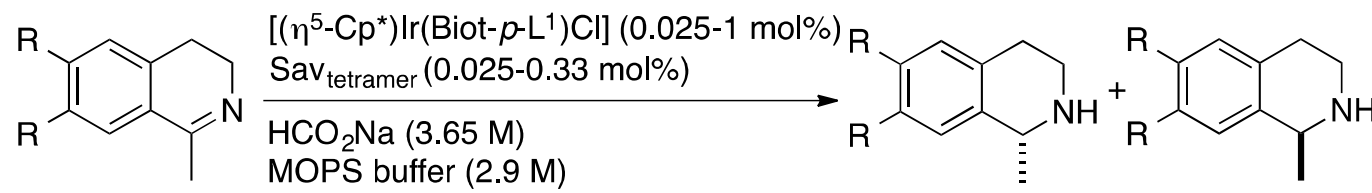

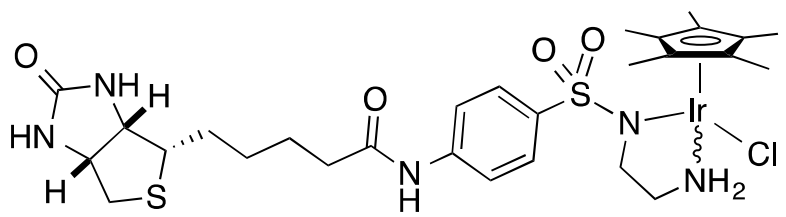

$\left[\left(\eta^{5}-\mathrm{C} p^{*}\right) \operatorname{Ir}\left(\right.\right.$ Biot $\left.\left.-p-L^{1}\right) \mathrm{Cl}\right] \mathbf{C 1}$

\begin{tabular}{|c|c|c|c|c|c|c|c|c|c|}
\hline Sav & $S$ & $\begin{array}{cc}\mathrm{pH} & \mathrm{T} \\
& \left({ }^{\circ} \mathrm{C}\right) \\
\end{array}$ & $\begin{array}{l}\text { [cat] } \\
(\mu \mathrm{M}) \\
\end{array}$ & $\begin{array}{c}\mathrm{t} \\
\text { (h) }\end{array}$ & $\begin{array}{c}\text { ratio } \\
{[\mathrm{Ir}] /\left[\mathrm{Sav}_{\text {tetr }}\right]}\end{array}$ & $\begin{array}{c}k_{\mathrm{cat}} / \mathrm{K}_{\mathrm{M}} \\
\left(\mathrm{min}^{-1} \mathrm{M}^{-1}\right)\end{array}$ & $\begin{array}{c}e e \\
(\%) \\
\end{array}$ & TON & Ref \\
\hline $\begin{array}{r}\text { WT } \\
\text { S112A } \\
\text { S112A } \\
\text { S112A } \\
\text { S112K } \\
\text { S112K } \\
W T \\
\text { S112A-K112A }\end{array}$ & $\begin{array}{l}2 \\
2 \\
2 \\
2 \\
2 \\
2 \\
2 \\
4 \\
4\end{array}$ & $\begin{array}{lc}7.3 & 25 \\
7.3 & 55 \\
7.3 & 55 \\
6.5 & 5 \\
6.5 & 5 \\
7.5 & 5 \\
7.5 & 24 \\
7.8 & 37 \\
7.8 & 37\end{array}$ & $\begin{array}{l}690 \\
690 \\
690 \\
690 \\
17 \\
690 \\
25 \\
93 \\
23\end{array}$ & $\begin{array}{c}5 \\
2 \\
2 \\
24 \\
96 \\
48 \\
0.75 \\
18 \\
18\end{array}$ & $\begin{array}{c}- \\
3 \\
3 \\
3 \\
1 \\
3 \\
1 \\
1.5 \\
1.5\end{array}$ & $\begin{array}{c}- \\
- \\
- \\
- \\
217 \\
- \\
7 \\
189 \\
1591\end{array}$ & $\begin{array}{c}\text { rac. } \\
57(R) \\
79(R) \\
91(R) \\
96(R) \\
78(S) \\
70(S) \\
60(R) \\
47(R)\end{array}$ & $\begin{array}{l}>100 \\
>100 \\
>100 \\
>100 \\
>4000 \\
>100 \\
- \\
>92 \\
>435\end{array}$ & $\begin{array}{l}30 \\
30 \\
30 \\
30 \\
30+36 \\
30 \\
36 \\
33 \\
33\end{array}$ \\
\hline
\end{tabular}

Scheme 2. Genetic optimization of an artificial imine reductase.

For the optimization of ArMs, past experience suggested that positions Sav S112 and Sav K121 lie closest to a biotinylated cofactor bearing a short spacer. ${ }^{28}$ Screening a focused library of single- and double point mutants in the presence of $\mathbf{C 1}$ lead to the identification of highly active and selective artificial imine reductases for the production of enantioenriched amines $\mathbf{1}$ and $\mathbf{3}^{30}$

i) At pH 6.5 and $5{ }^{\circ} \mathrm{C} \mathrm{C1} \cdot \mathrm{Sav} \mathrm{S} 112 \mathrm{~A}$ yielded $(R)-1$ in $91 \%$ ee and $>100 \mathrm{TON}$ (total turnover number) after $24 \mathrm{~h}$.

ii) $\quad$ C1 $\cdot$ Sav S112K lead to $(S)-1$ with $78 \%$ ee at $5{ }^{\circ} \mathrm{C}$ and $\mathrm{pH} 7.5$.

iii) Improvement of the kinetic parameters could be achieved upon introduction of alanine residues at both $\mathrm{S} 112$ and K121 positions: compared to the WT variant, the catalytic efficiency of the double mutant C1 Sav S112A K121A was increased 7.6 fold vs. WT for the reduction of prochiral imine $4 .{ }^{33}$ 
iv) Reducing the catalyst concentration to $17 \mu \mathrm{M}(0.025 \mathrm{~mol} \%$ loading $)$ yielded $>$ 4'000 TON for $\mathbf{C} 1 \cdot$ Sav S112A.

IrCp*-based complexes are also known to catalyze the chemoselective reduction of enones. ${ }^{43}$ We thus anticipated that the $\mathbf{C} \mathbf{1} \cdot$ Sav may also catalyze the reduction of enones to afford the corresponding ketone via 1,4 -addition.

To test this, we designed a cyclohexenone derivative $\mathbf{5}$ which, upon reduction undergoes spontaneous E1cB elimination to afford enone 6, releasing the fluorescent umbelliferone. ${ }^{29}$ At room temperature fluorescence develops only in presence of catalyst C1 Sav. Strikingly, the reaction proceeds even under very dilute conditions: $1 \mu \mathrm{M} \mathrm{C1}$ and $100 \mu \mathrm{M}$ substrate. Genetic optimization relying on fluorescence led to the identification of Sav K121F (147 AU $\cdot \mathrm{min}^{-1}$ compared to $7.5 \mathrm{AU} \cdot \mathrm{min}^{-1}$ for $\mathbf{C 1}$. WT Sav) suggesting that protein-substrate interactions are dominated by aromatic interactions, Scheme 3a.

With in vivo applications in mind, the best $\mathbf{C 1} \cdot$ WT Sav was encapsulated into a biocompatible, cellpenetrating polymersome consisting of block-copolymers poly(2-methyloxazoline)- $\beta$ poly(dimethylsiloxane)- $\beta$-poly(2-methyloxazoline) (PMOXA- $\beta$-PDMS- $\beta$-PMOXA) developed by Meier. ${ }^{44}$ Although less active than the non-encapsulated ArM, the activity could be slightly improved upon insertion of a bacterial outer-membrane pore protein $\mathrm{F}(\mathrm{ompF})$ into the polymersome, Scheme $3 b$. 
a)

\subsection{Abiotic $\mathrm{C}-\mathrm{C}$ bond forming reactions.}

2.2.1 Introduction Among the numerous abiotic reactions catalyzed by precious metals, $\mathrm{C}-\mathrm{C}$ bond forming reactions have been extensively scrutinized. Importantly, these reactions have no equivalent in the enzymatic repertoire and the reagents display limited cross reactivity in a cellular environment (i.e. bioorthogonality). ${ }^{45}$ With the aim of complementing the natural enzyme's repertoire, we thus set out to develop ArMs for these reactions.

\subsubsection{An artificial metathase based on the biotin-streptavidin technology. Ring-closing metathesis} $(\mathrm{RCM})$ is a widely applicable reaction for the intramolecular formation of internal $\mathrm{C}=\mathrm{C}$ double bonds from olefins. One of the most widely used catalysts is the Grubbs-Hoyveda $2^{\text {nd }}$ generation complex. Importantly, it is water compatible. ${ }^{46}$ Following our well-established strategy, we set out to investigate and improve the potential of a biotin-bearing Grubbs-Hoyveda second generation complex in the presence of (strept)avidin for RCM. We initially synthesized two biotinylated $N$-heterocyclic carbenes and scrutinized their potential to localize the $\{\mathrm{Ru}($ alkylidene) $\}$-moiety within (strept)avidin, Scheme 4. 
In our initial report, the D-biotin anchor was linked to the imidazole moiety of the NHC Grubbs Hoyveda $2^{\text {nd }}$-generation complex: $\left(\right.$ Biot- $\left.\mathrm{L}^{2}\right)$ and $\left(\right.$ Biot- $\left.m-\mathrm{ABA}-\mathrm{L}^{2}\right)$. For screening purposes, we selected the hydrophobic $N$-tosyl diallyl amine 7.

Avidin (Avi) proved to be a better host than streptavidin: $\left[\mathrm{RuCl}_{2}\left(\mathrm{Biot}_{-} \mathrm{L}^{2}\right)(\right.$ alkylidene $\left.)\right] \cdot$ WT Avi yielded up to 19 turnovers; $\left[\mathrm{RuCl}_{2}\left(\right.\right.$ Biot- $\left.m-\mathrm{ABA}-\mathrm{L}^{2}\right)($ alkylidene) $] \cdot$ WT Sav afforded 14 TONs, Scheme 4. However, the artificial metathase did not outperform the free $\left[\mathrm{RuCl}_{2}\left(\mathrm{Biot}-\mathrm{L}^{2}\right)\right.$ (alkylidene) $]$.

To improve the performance of the artificial metathase, we synthesized a library of biotinylated-NHC ligands. ${ }^{40}$ We could show that two mesityl substituents are required and that the biotin anchor is best placed on one of these aryl groups. To overcome the very limited aqueous solubility of substrate 7, we used its cationic analog 9. Screening a small library of Sav mutants led to the identification of $\left[\mathrm{RuCl}_{2}\left(\mathrm{Biot}_{-} \mathrm{L}^{3}\right)(\right.$ alkylidene) $] \mathbf{C 4} \cdot \mathrm{Sav} \mathrm{K} 121 \mathrm{~A}: 66 \mathrm{TON}$ were obtained for the RCM of substrate 9 (free cofactor $\mathbf{C} 4$ affords only 38 TONs, Scheme 4$){ }^{47}$

In stark contrast to the imine reductase, we could show that the artificial metathase is remarkably tolerant toward cellular extracts. These observations thus open fascinating perspectives towards RCM in vivo.

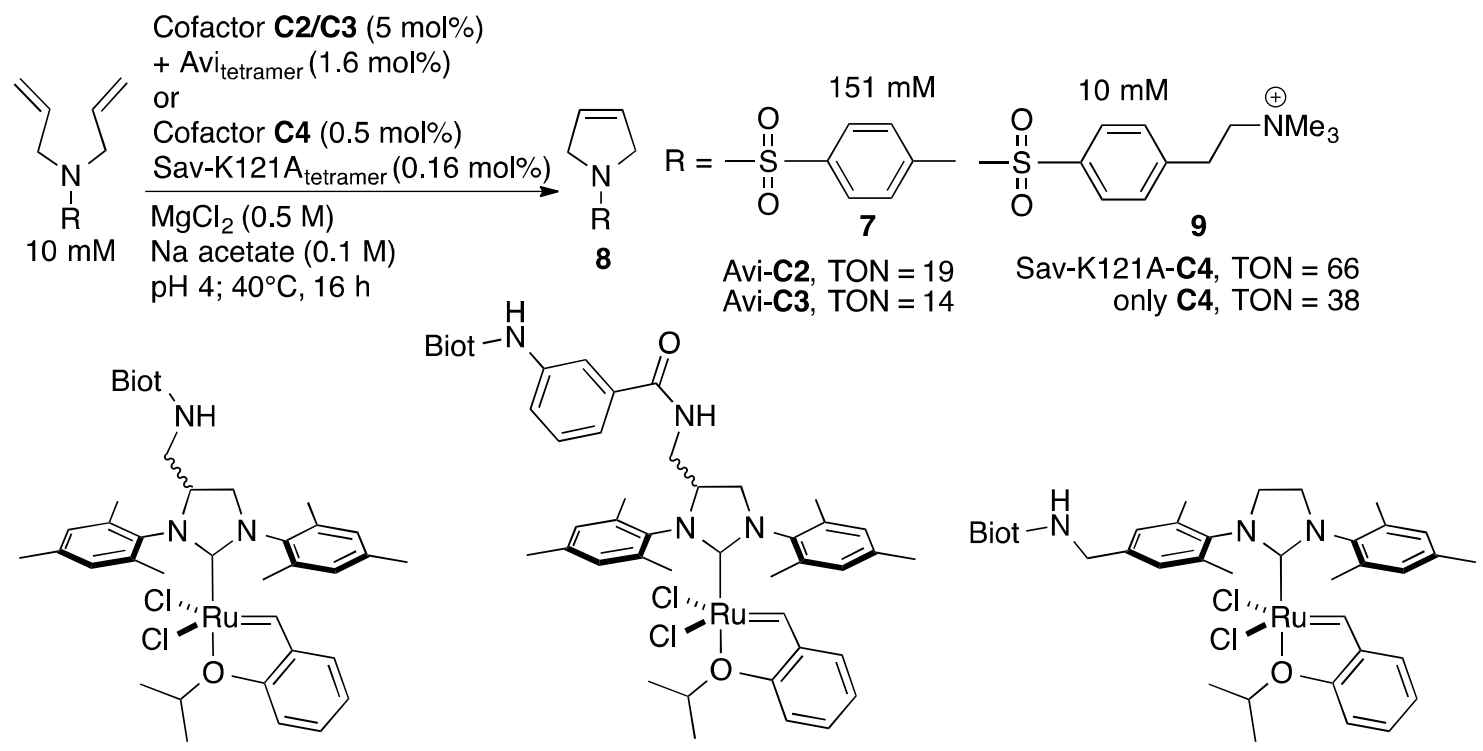

$\left[\mathrm{RuCl}_{2}\left(\right.\right.$ Biot-L2)(alkylidene)] $\mathbf{C 2} \quad\left[\mathrm{RuCl}_{2}\left(\right.\right.$ Biot- $\left.m-\mathrm{ABA}-\mathrm{L}^{2}\right)$ (alkylidene) $] \mathbf{C 3} \quad\left[\mathrm{RuCl}_{2}\left(\right.\right.$ Biot- $\left.^{3}\right)$ (alkylidene) $] \mathrm{C4}$ Scheme 4. An artificial metathase based on the biotin-streptavidin technology. 
2.2.3 An artificial Suzukiase. Having previously reported on an artificial allylic alkylase based on a biotinylated palladium diphosphine, ${ }^{23}$ we speculated that it may be possible to extend this strategy to Suzuki cross-coupling reactions. We hypothesized that this reaction may be amenable to in vivo catalysis, thanks to the bio-orthogonality of both reactants: aryl halides and boronic acids.

The chemical diversity was achieved by screening a variety of biotinylated NHC ligands (vide supra) and biotinylated monophosphines, Scheme 5. In the presence of WT Sav, the $\left[\operatorname{Pd}\left(\eta^{3}-\right.\right.$ cinnamyl)Cl(Biot-L $\left.{ }^{2}\right)$ ] performed poorly whereas the Suzukiase with the bulky and electron-rich phosphine $\left[\mathrm{Pd}\left(\eta^{3}-\right.\right.$ cinnamyl $) \mathrm{Cl}\left(\operatorname{Biot}-\mathrm{Et}-\mathrm{P}(t-\mathrm{Bu})_{2}\right]$ C6 $\cdot \mathrm{WT}$ Sav and $\left[\mathrm{Pd}\left(\eta^{3}-\right.\right.$ cinamyl $) \mathrm{Cl}(\operatorname{Biot}-\mathrm{Pr}-\mathrm{P}(t-$ $\left.\mathrm{Bu})_{2}\right] \mathbf{C 7} \cdot$ WT Sav afforded the methoxy-binaphtyl $\mathbf{1 0}$ with 78 and 73 TONs respectively. The length of the spacer had a dramatic influence on the enantioselectivity: $(R)-\mathbf{1 0}(58 \%$ ee) was formed preferentially with the ethyl spacer and $(S)-\mathbf{1 0}\left(10 \%\right.$ ee) with the propyl spacer. $\operatorname{The}\left[\operatorname{Pd}\left(\eta^{3}-\right.\right.$ cinnamyl)Cl(Biot-Et-PPh 2$)] \cdot$ WT Sav also afforded the $(R)-\mathbf{1 0}$ but in lower conversion $(42 \%$ ee, 45 TONs). In comparison, the TON was reduced fourfold in the absence of Sav, highlighting the favourable environment provided by the protein on the catalytic performance. For genetic optimization purposes, both $\mathbf{C 6}$ and $\mathbf{C 7}$ were screened with a focused library of Sav mutants: up to $90 \%$ ee $(R)-\mathbf{1 0}$ was obtained with C6 $\cdot$ Sav S112Y-K121E (50 TONs at $4^{\circ} \mathrm{C}$ ) and $47 \%$ ee, $(S)$-10 in the presence of C6 Sav K121A, (32 TONs at room temperature). Enantioselective Suzuki-cross coupling in water is rare $^{48}$ This may be traced back to the propensity of palladium to form highly active achiral nanoparticles in water. 


\section{Protein-accelerated catalysis: precatalyst activation upon incorporation}

\section{within streptavidin}

3.1 Introduction In contrast to evolving natural enzymes in vivo, ArMs rely on exogeneous cofactors which must be added to the Sav to form the holoenzyme. More often than not, the biotinylated cofactors are active even in the absence of Sav. With the goal of performing catalysis in vivo, we speculated that developing an inactive precatalyst that would be activated only upon incorporation within Sav would be highly desirable. We selected $d^{6}$-pianostool complexes as these have shown: i) to have a great potential in a variety of homogeneous catalytic transformations ${ }^{49}$ and ii) promising tolerance towards cellular extracts. ${ }^{50}$ To allow for broad applicability, we introduced a biotin anchor on the cyclopentadienyl moiety. Modelling studies revealed that an ethyl spacer between the biotin and the $\mathrm{Cp}$ *-moiety would place the corresponding complex in the proximity of residues $\mathrm{S} 112$ and K121 within Sav. ${ }^{35}$ To investigate the validity of the approach, we selected the Rh-catalyzed $\mathrm{C}-\mathrm{H}$ activation and the ATHase reactions.

\subsection{Biotinylated Rh(III) pianostool complex in engineered streptavidin for accelerated} asymmetric $\mathbf{C}-\mathbf{H}$ activation 
Activation of $\mathrm{sp}^{2} \mathrm{C}-\mathrm{H}$ bonds by a $\left[\left(\eta^{5}-\mathrm{Cp}^{*}\right) \mathrm{RhCl}_{2}\right]_{2}$ pianostool catalyst is a powerful tool to functionalize arenes with alkyl or vinyl substituents via $\mathrm{C}-\mathrm{C}$ bond formation. ${ }^{51}$ Starting from pivaloylprotected benzhydroxymic acid 11, isoquinolone $\mathbf{1 2}$ is formed upon reaction with mthylacrylate. We hypothesized that the artificial benzannulase $\left[\left(\right.\right.$ Biot-Et- $\left.\left.\eta^{5}-\mathrm{Cp}^{*}\right) \mathrm{MCl}_{2}\left(\mathrm{H}_{2} \mathrm{O}\right)\right] \cdot \mathrm{Sav}$ might allow to control both the regio- and the stereoselectivity of this reaction. Initial experiments with [(Biot-Et- $\eta^{5}-$ $\left.\left.\mathrm{Cp}^{*}\right) \mathrm{RhCl}_{2}\left(\mathrm{H}_{2} \mathrm{O}\right)\right] \mathbf{C 1 0} \cdot$ WT Sav revealed good activity and moderate selectivity in the presence of an acetate buffer $(0.68 \mathrm{M})$. Indeed, the rate determining step is the Concerted Metallation-Deprotonation step (CMD) whereby the $N$-bound rhodium activates the ortho- $\mathrm{C}_{\text {aryl }}-\mathrm{H}$ bond. $\mathrm{In}$ a $\mathrm{MeOH}: \mathrm{H}_{2} \mathrm{O} 1: 4$ mixture, 23 TONs with a $9: 1$ regioisomeric ratio and a $50 \%$ ee in favor of the $(R)$-isoquinolone 12 were obtained. The free cofactor afforded 40 TONs with a $4: 1$ regioisomeric ratio and $(\mathrm{rac})-\mathbf{1 2}$. With the aim of activiting the cofactor $\mathbf{C 1 0}$ upon incorporation in Sav, we screened a variety of mutants bearing a carboxylate residue in the proximity of the Rh-moiety. We were delighted to observe significant amounts of $(R)-\mathbf{1 2}(56 \%$ ee, 45 TON, $15: 1$ regioisomer ratio) in the presence of $\mathbf{C 1 0}$. Sav K121E, even without added base. This suggests that the glutamate acts as a base to deprotonate the ortho- $\mathrm{C}_{\mathrm{aryl}}-\mathrm{H}$ bond. In order to improve the enantioselectivity, we screened a variety of Sav mutants. Gratifyingly, combining the selective S112Y mutant with the highly active K121E mutant yielded a highly active and highly selective benzannulase C10 $\cdot$ Sav S112Y-K121E: $(R)-\mathbf{1 2}$ could be isolated in $82 \%$ ee, 48 TONs and a $19: 1$ regioisomer ratio), Scheme 6 a.

Using an ortho-mono-deuterated benzamide 11, a kinetic isotopic effect (KIE) of 4.8 was determined. This confirms that the rate determining step of the benzannulation is the CMD step, Scheme 6b. For comparison, $\mathbf{C 1 0} \cdot$ WT Sav had KIE $=2.8$.

Upon varying the $\mathrm{Rh}$ : Sav ratio, the rate-enhancing effect of the engineered basic residue at position 121 was estimated to be 100 . 
a)

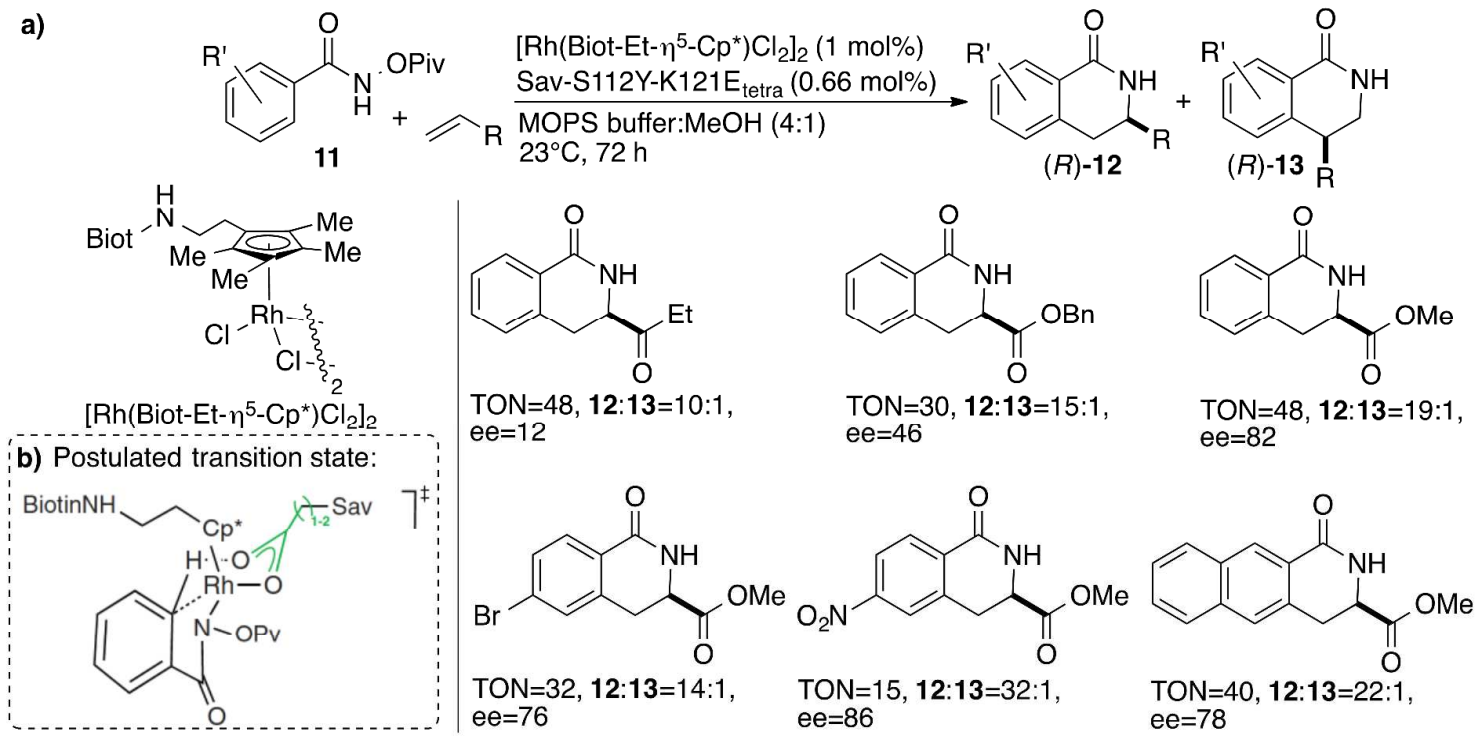

Scheme 6. An artificial benzannulase for the synthesis of enantioenriched dihydroisoquinolones. Reaction conditions and substrate scope a) and postulated transition state of the CMD step b).

\subsection{Activation of a biotinylated Rh(III) pianostool complex by histidine coordination for asymmetric transfer hydrogenation}

With the aim of extending the activation strategy outlined for the rhodium-catalyzed $\mathrm{C}-\mathrm{H}$ activation step, we reasoned that the transfer hydrogenation activity of $\left[\left(\right.\right.$ Biot-Et- $\left.\left.\eta^{5}-\mathrm{Cp}^{*}\right) \mathrm{MCl}_{2}\left(\mathrm{H}_{2} \mathrm{O}\right)\right](\mathrm{M}=$ $\mathrm{Rh}(\mathrm{III}), \operatorname{Ir}(\mathrm{III}))$ may be significantly enhanced upon coordination to a nucleophilic amino acid. We hypothesized that mutants Sav S112H or Sav K121H may bind to [(Biot-Et- $\left.\left.\eta^{5}-\mathrm{Cp}^{*}\right) \mathrm{MCl}_{2}\left(\mathrm{H}_{2} \mathrm{O}\right)\right]$. We thus compared the activity of $\left[\left(\right.\right.$ Biot-Et- $\left.\left.\eta^{5}-\mathrm{Cp}^{*}\right) \mathrm{MCl}_{2}\left(\mathrm{H}_{2} \mathrm{O}\right)\right]$ in combination with WT Sav, Sav S112H or Sav K121H in the asymmetric transfer hydrogenation of imine 2 to afford salsolidine $\mathbf{1}$. From these experiments, the following features emerge:

i) Upon incorporation of $\left[\left(\right.\right.$ Biot-Et- $\left.\left.\eta^{5}-\mathrm{Cp}^{*}\right) \mathrm{MCl}_{2}\left(\mathrm{H}_{2} \mathrm{O}\right)\right](\mathrm{M}=\mathrm{Rh}(\mathrm{III}), \mathrm{Ir}(\mathrm{III}))$ into WT Sav, both the activity and selectivity remained virtually unaffected ( $r a c-1$ and $6 \%(S)-1$ for Rh and Ir respectively).

ii) Upon incorporation of $\mathbf{C 1 0}$ in $\mathrm{Sav} \mathrm{S} 112 \mathrm{H},(S)$-salsolidine $\mathbf{1}$ is produced with up to $55 \%$ ee and TON $>100$ at $55^{\circ} \mathrm{C}$ and $\mathrm{pH}=5.0$, Scheme $7 \mathrm{a}$. 
iii) In contrast, $\mathbf{C 1 0} \cdot \mathrm{Sav} \mathrm{K} 121 \mathrm{H}$ affords $(R)$-salsolidine $\mathbf{1}$ in $79 \%$ ee and $>100 \mathrm{TON}$ at $55^{\circ} \mathrm{C}$ and $\mathrm{pH}$ $=5.0$, Scheme 7a. Upon decreasing the temperature, both the TON and the enantioselectivity decreased for both ATHases: for $\mathbf{C 1 0} \cdot \mathrm{Sav} \mathrm{K} 121 \mathrm{H}$, at $25{ }^{\circ} \mathrm{C},(R)$-salsolidine $\mathbf{1}$ is produced with TON $=12$ and ee $50 \%(R)-1$.

The histidine-coordination to $\mathbf{C 1 0}$ was confirmed by X-ray crystallography for both ATHases [(BiotEt- $\left.\left.\eta^{5}-\mathrm{Cp}^{*}\right) \mathrm{RhCl}_{2}\left(\mathrm{H}_{2} \mathrm{O}\right)\right] \cdot \mathrm{Sav} \mathrm{K} 121 \mathrm{H}$ and $\mathbf{C 1 0} \cdot \mathrm{Sav} \mathrm{S} 112 \mathrm{H}$. The two structures revealed a pseudomirror image relationship between the two mutants, thus providing a hint as to why the ATHases produce $(S)$ - and $(R)$-salsoline 1 depending on the position of the histidine, Scheme 7b, c.<smiles>COc1cc2c(cc1OC)C(C)=NCC2</smiles>
$22.9 \mathrm{mM}$

b)

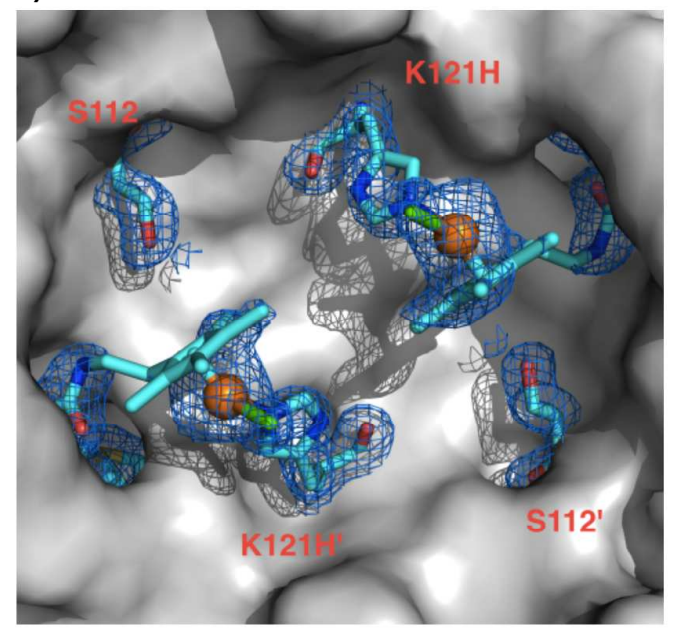

$\left[\mathrm{Rh}\left(\text { Biot-Et- } \eta^{5}-\mathrm{Cp}^{\star}\right) \mathrm{Cl}_{2}\right]_{2}$ (2 mol\%) $\operatorname{Sav}_{\text {tetramer }}(1 \mathrm{~mol} \%)$ $\mathrm{HCO}_{2} \mathrm{Na}(3.65 \mathrm{M})$ MOPS buffer $(2.9 \mathrm{M})$ $\mathrm{pH} 5,55^{\circ} \mathrm{C}$ rhodium.

Scheme 7. A dual-anchoring strategy for the localization and activation of $\mathbf{C 1 0}$ within streptavidin. Genetic optimization of the performance of the ATHase activity a); X-ray structure of C10 - Sav $\mathrm{S} 112 \mathrm{H} \mathrm{b}$ ) and $\mathbf{C 1 0} \cdot$ Sav $\mathrm{K} 121 \mathrm{H} \mathrm{c}$ ) revealing the pseudo-mirror image environment around the 


\section{High-throughput screening of ArMs: overcoming the streptavidin} purification bottleneck

4.1 Neutralizing glutathione To date, most of the effort in the field of ArMs has been centered around the use of precious metals..$^{10,52,53}$ While these metals provide versatile tools towards the implementation of new-to-nature reactivities, their soft-character renders them susceptible to poisoning via coordination to thiols. In particular, glutathione (GSH hereafter) is typically present in $\mathrm{mM}$ concentrations in aerobic cells. ${ }^{54}$ Exploratory experiments with the biotinylated cofactors presented above revealed that super-stoichiometric amounts GSH $(<10$ equivalents $v s$. precious metal $)$ irreversibly inhibit their catalytic performance. This sets a severe restriction on the prospect of screening unpurified protein samples. In stark contrast, the oxidized disulfide form of glutathione (GSSG hereafter) is less detrimental to the catalytic performance of the biotinylated metal cofactors. We thus set out to evaluate in the presence of $\left[\left(\eta^{5}-\mathrm{Cp}^{*}\right) \operatorname{Ir}\left(\right.\right.$ Biot $\left.\left.-p-\mathrm{L}^{1}\right) \mathrm{Cl}\right]$-based ATHases (Scheme 2), the effect of a selection of known GSH-neutralizing agents, Scheme 8. Initial experiments were performed by spiking purified Sav samples with $2.5 \mathrm{mM} \mathrm{GSH}$. The effect of the GSH-neutralizing agents was then evaluated in the presence of either C1 $\cdot$ Sav S112A (to produce preferentially $(R)-\mathbf{1}$ ) or C1 - Sav S112K (to produce preferentially $(S)-\mathbf{1})$. Under these "rehearsal" conditions, diamide DiAm, 2-bromo-acetophenone BrPheOne and phenyl-vinylsulfone PheViSul proved most promising, Scheme 8 . However, the neutralizing agent $(5-10 \mathrm{mM})$ needed to be allowed to react overnight prior to the addition of the $\mathbf{C} \mathbf{1}$ cofactor. The ATHase activity of $\mathbf{C} \mathbf{1} \cdot$ Sav S112A was nearly restored in the presence of DiAm (TON > 90 and ee comparable to unspiked samples. For the C1 $\cdot$ Sav S112K, the effect of DiAm was less pronounced. ${ }^{34}$

Next, the GSH neutralizing agents were tested in the presence of E. coli cell free extracts which contained only the soluble fraction of the cell lysate including Sav. Here, DiAm clearly outperformed BrPheOne and PheViSul. At $10 \mathrm{mM}$ DiAm and two hours preincubation, $>50 \%$ of the activity obtained with purified Sav samples could be recovered with identical enantioselectivity. In the presence of cell lysates, the TON and ee for ATHase Sav S112K were nearly identical (64 \% residual TON and $-68 \%$ ee). For ATHase with Sav S112A, $23 \%$ residual TON and $70 \%$ ee were obtained. ${ }^{34}$ 


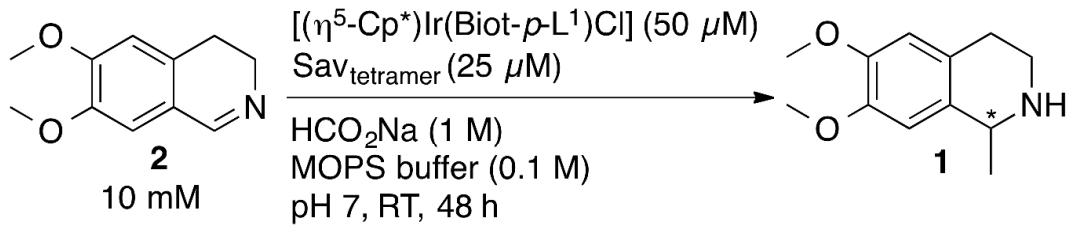

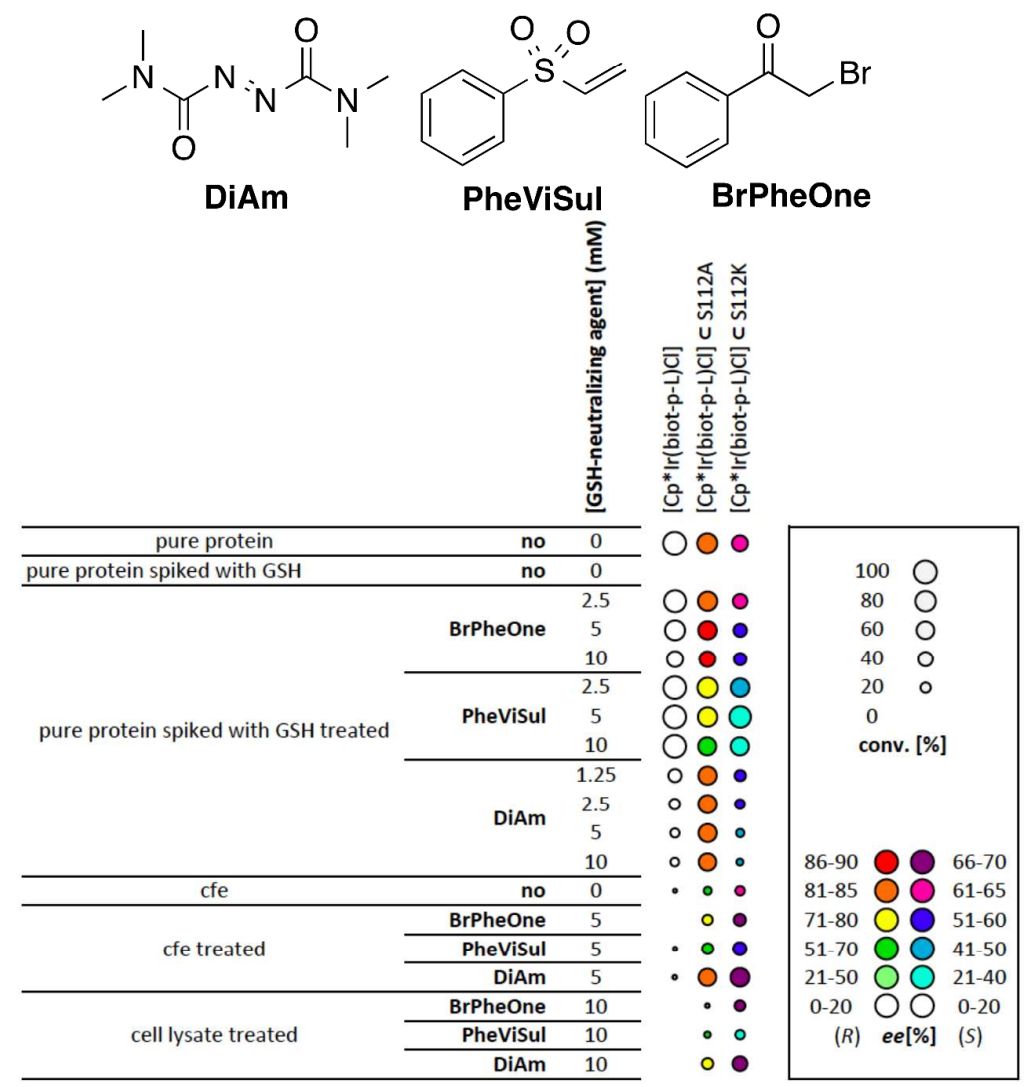

Scheme 8. Identification of a suitable glutathione (GSH) neutralizing agent for screening ATHase in the presence of $E$. coli cell-free extracts.

From these studies, we conclude that soluble thiol-containing peptides and proteins are indeed inhibitors for C1. Addition of DiAm allows to overcome this limitation and screen cell free extracts.

4.2 Multiwell-plate streptavidin expression Having identified a means to screen E. coli cell-free extracts containing Sav isoforms for ATHase activity, it remained to develop a streamlined protocol for the parallel expression of the host proteins. 
Past experience suggests that one milligram of tetrameric streptavidin is sufficient to perform 2-3 catalytic experiments. Such Sav quantities can routinely be produced in five milliliter E. coli cultures. We thus established a 24 deep well-plate expression and screening platform. Inspection of the crystal structures of Sav-based ArMs revealed 28 amino acid positions that lie within $15 \AA$ of the metal. These were selected for site-directed mutagenesis. Rather than using degenerate codons, a strategy relying on precise primers was implemented for the following reasons: i) it limits the screening effort as no oversampling is required and ii) it allows to freely select the mutation to be introduced at each position. The following amino acid mutations were selected for the twenty eight positions: A, V, L, D, E, Q, K, H, M, Y, S, P to afford 334 Sav isoforms. As the presence of a lysine at position 121 was shown to be detrimental both in terms of Sav expression levels and in terms of catalytic performance for various ArMs, ${ }^{33,47}$ the Sav K121A was selected as the background Sav from which all mutations were introduced.

Mutations were introduced using the Quick-change PCR in a 96-well format. Next, point-mutated pET24a-SAV vectors were transformed into E. coli BL21 (DE3) and Sav expression was performed in 24-well format using auto-induction medium ZYP-5052. After $24 \mathrm{~h}$, the cells were harvested by centrifugation and lysed to obtain cell lysates. The Sav concentration (i.e. free biotin-binding sites) within the cell-lysates or the cell-free extracts was determined by a single point determination using biotin-4-fluorescein. ${ }^{47}$

Two complementary strategies for ArM screening are pursued in the Ward group: either diamide treatment to neutralize GSH or reversible immobilization of sepharose imminobiotin beads.

For ATHase, the cell-free extracts are treated with diamide DiAm prior to addition of $\mathbf{C 1}$ and subsequent catalysis in $200 \mu \mathrm{L}$ total volume. Reaction progress and quantification can readily be perfomed by HPLC analysis, Scheme 9 option A. ${ }^{47}$

For metathesis screening, a straightforward Sav immobilization protocol was implemented. The cellfree extracts containing the Sav isoform are treated with iminobiotin-sepharose at $\mathrm{pH}=9$. At this $\mathrm{pH}$, Sav binds tightly to iminobiotin, thus allowing to remove all other cell-debris by simple 
centrifugation. Acidification protonates the iminobiotin, thus releasing the semi-purified Sav sample. As the metathesis is performed under acidic conditions, ideally $\mathrm{pH}=4$, the biotinylated cofactor $\mathbf{C 4}$ can be added directly to the immobilized Sav in the reaction buffer, Scheme 9 option B. ${ }^{47}$

These protocols are suited for the semi-automated in vitro directed evolution protocols of ArMs based on the biotin-avidin technology.
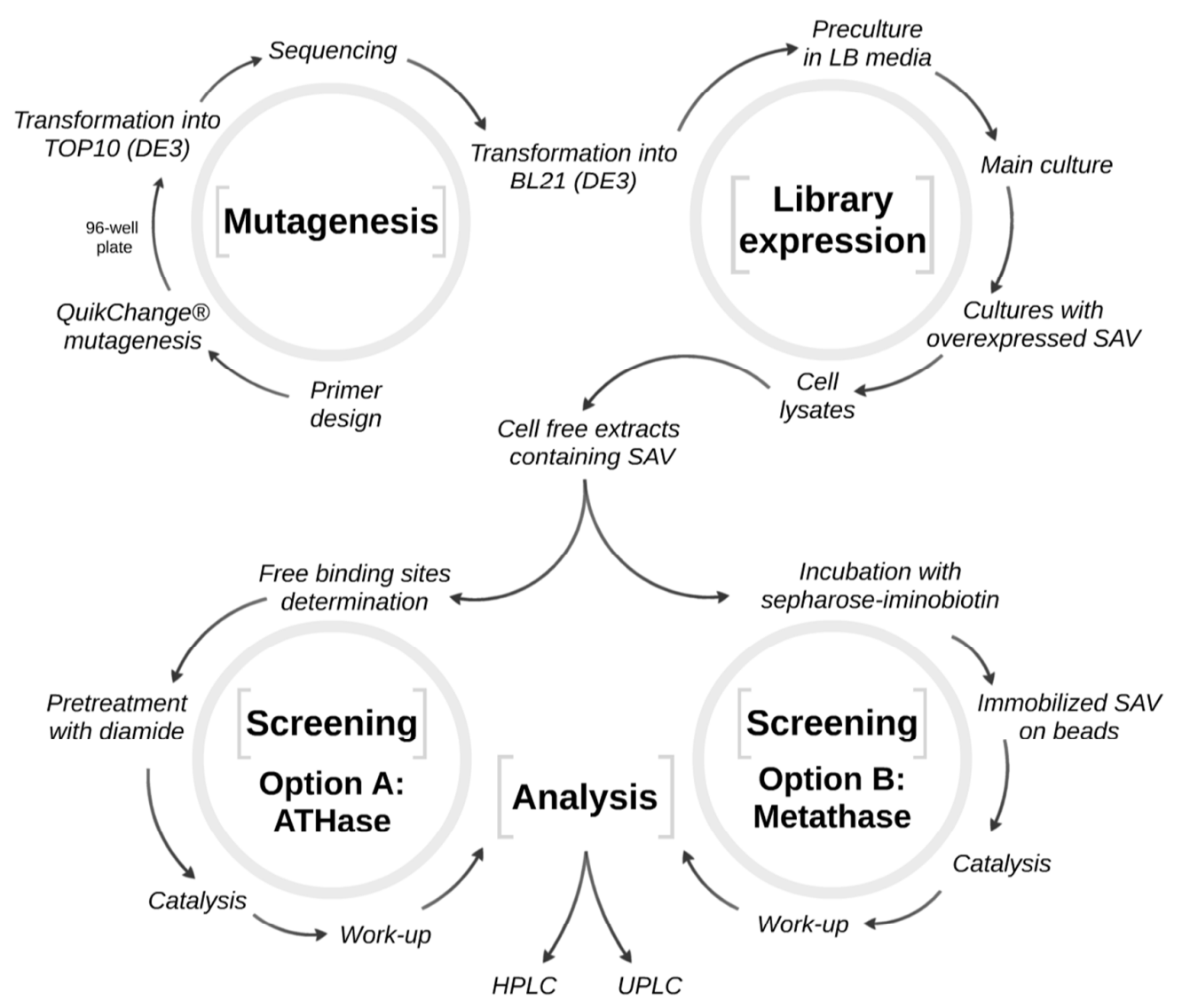

Scheme 9. A streamlined protocol for the production and the screening of streptavidin mutants. Diamide treatment for ATHase screening (Option A) and reversible immobilization on iminobiotinsepharose for metathase screening (Option B). Adapted with permission from ref. [47]. Copyright [2016] [MacMillan]. 


\section{Engineering cascades with artificial metalloenzymes}

5.1 Background Having demonstrated the compatibility of ArMs with cellular components, including other enzymes present in cell-free extracts, we set out to investigate the possibility of engineering enzyme cascades. In their natural environment, enzymes have evolved to operate in the presence of other enzymes, thus rendering these systems ideally suited to engineer cascades. Organometallic catalysts and enzymes however often suffer from mutual inhibition. To overcome this challenge, a compartmentalization strategy has proven versatile. ${ }^{55,56}$ We hypothesized that embedding a biotinylated organometallic cofactor within Sav may effectively shield it from undesirable interactions with a partner enzyme. To test this, we selected the ATHase $\left[\left(\eta^{5}-\mathrm{Cp}^{*}\right) \operatorname{Ir}\left(\right.\right.$ Biot $\left.\left.-p-\mathrm{L}^{1}\right) \mathrm{Cl}\right] \cdot$ Sav and tested its compatibility with a variety of natural enzymes.

5.2. Enzyme cascades relying on amine oxidases and ATHases We initially set out to combine an ArM's-catalyzed imine reduction with a natural amine oxidase. The ATHase C1 $\cdot$ Sav S112T, which displays modest $(R)$-selectivity for the imine 4 (59 \% ee) was combined with monoaminooxidase-N-9 (MAO-N-9). This enzyme, displays near perfect $(S)$-selectivity towards a variety of amines to afford the corresponding imines using dioxygen as oxidant. ${ }^{57}$ In a dynamic kinetic resolution, MAO-N-9 (re)oxidizes $(S)$-3 to the corresponding imine 4, leaving the enantiopure amine $(R)-\mathbf{3}$ untouched. Initial experiments combining MAO-N-9 and an ATHase were disappointing as the reaction rapidly stalled. We speculated that this may be due to the formation of hydrogen peroxide as side product of the amine oxidase activity. Addition of a catalase allowed to run concurrent enzyme cascades to afford $(R)$-amines ( $>99 \%$ ee), starting either from rac-amines or imines. Thanks to its near perfect selectivity, the overall enantioselectivity of the enzyme cascade is determined by the MAO-N-9.

Pursuing a similar enzyme cascade strategy, other enantiopure amines could be prepared, including pyrrolidines 15 and 17 as well as pipecolic acid 21, Scheme 10. Interestingly, the tertiary imine pseudooxynicotine 16 is reduced to the corresponding $(R)$-amine 17 with $>99 \%$ ee and 65 TON. At pH 7.5 pseudooxynicotine $\mathbf{1 6}$ is in equilibrium between the ring-open ketone $\mathbf{1 8}$ and the imine $\mathbf{1 6}$. The ATHase based on Sav S112A-K121T is imine 16 selective (76:11) to afford nicotine 17 whereas the ATHase-based on Sav S112G favours the alcohol 19 (3: 79), Scheme 10c. The chemoselectivity of 
ArMs bears great potential which may reveal further similarities between ArMs and natural enzymes. $^{31}$

a)

MAO-N

ATHase

catalase

13

b)

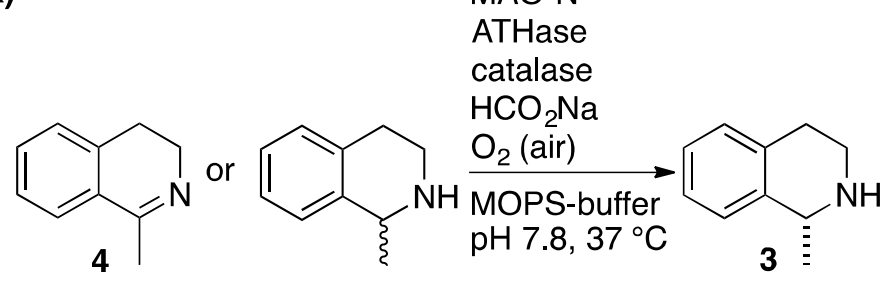

MAO-N

ATHase

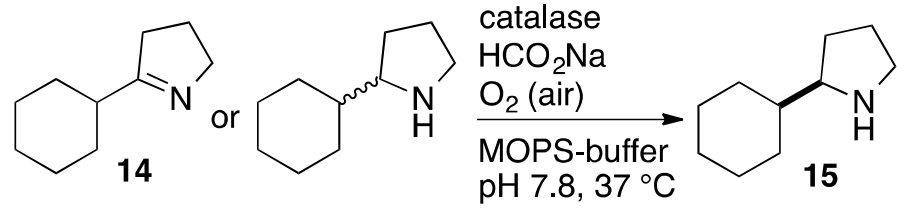

c)

MAO-N

ATHase
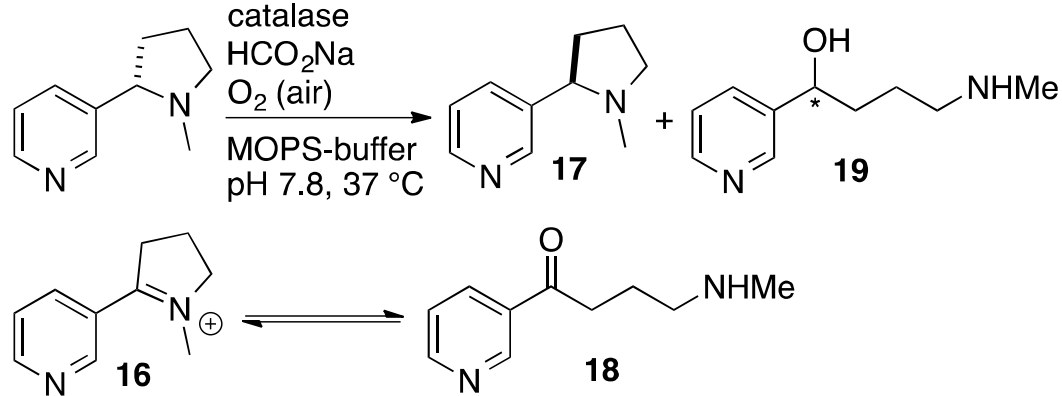

d)

LAAO

ATHase

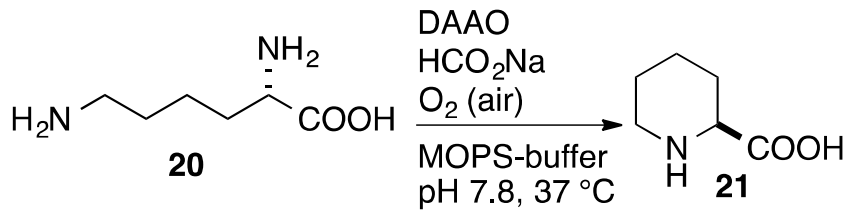

Scheme 10 Enzyme cascades combining an ATHase and an amine oxidase for the synthesis of enantiopure amines. Synthesis of isoquinolines and pyrrolidines a,b); nicotine c), and pipecolic acid d). Addition of either a horsereddish peroxidase or a catalase prevents the oxidation of the iridium cofactor by hydrogen peroxide.

5.3 ATHase for nicotinamide regeneration Although the cost of nicotinamides (NAD(P)H) has decreased in recent years, it contributes significantly to the operating costs of NAP(P)H-depedent purified enzyme processes. Many enzymatic NAD $(\mathrm{P})^{+}$-regeneration processes have been reported, ${ }^{58}$ 
but only few homogeneous organometallic $\mathrm{NAD}(\mathrm{P})^{+}$-regeneration systems have been demonstrated to operate in the presence of the NAD(P)H-dependent enzyme. ${ }^{59}$ Having demonstrated the compatibility of $\left[\left(\eta^{5}-\mathrm{Cp}^{*}\right) \operatorname{Ir}\left(\right.\right.$ Biot $\left.\left.-p-\mathrm{L}^{1}\right) \mathrm{Cl}\right] \cdot \mathrm{Sav}$ with a variety of oxidases and peroxidases, we tested its versatility for the regeneration of nicotinamides, Scheme 11. For this purpose, we selected the NADH-dependent hydroxybiphenyl monooxygenase (HbpA) and combined it with $\mathbf{C 1}$ - WT Sav. To our delight, 2hydroxybiphenyl 22 was converted to 1,2-dihydroxybiphenyl 23 (TON > 99) in the presence of dioxygen. In this cascade, water is produced as side product and thus no catalase is required, Scheme 11. ${ }^{31}$ Most recently, this strategy was extended to NADH-mimics that are compatible with enoate reductases. $^{60}$

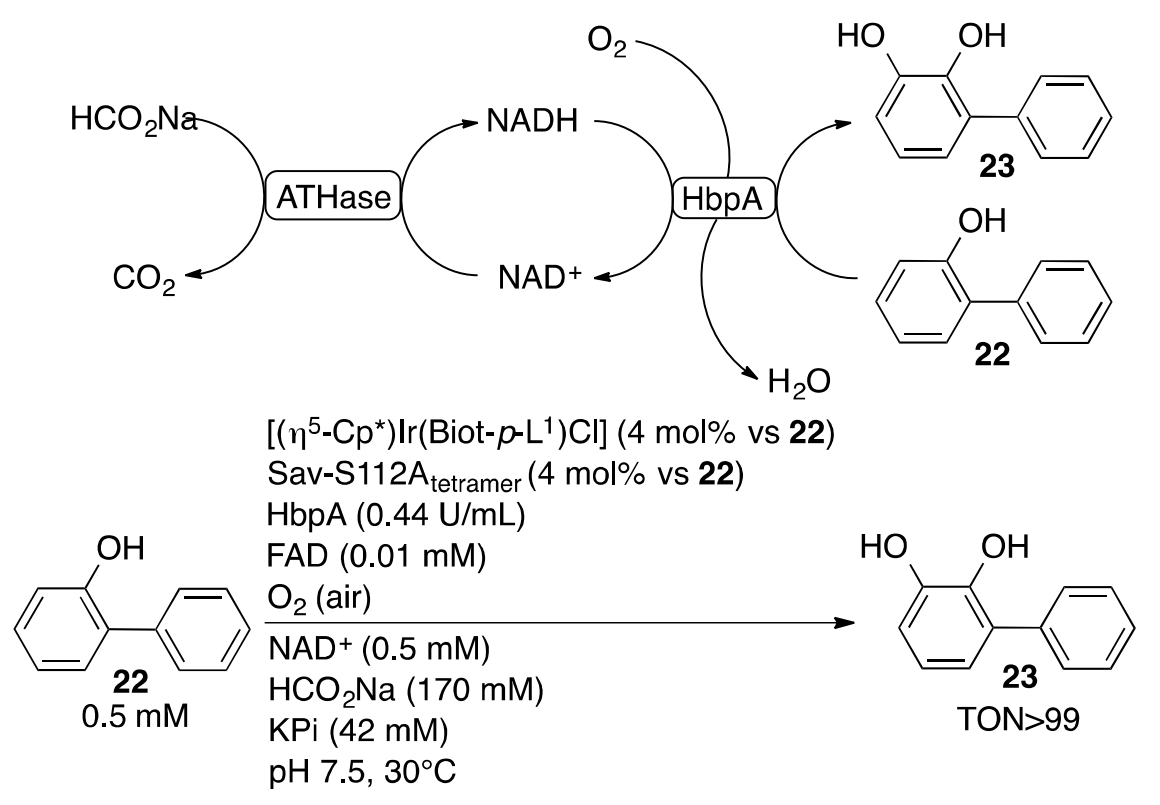

Scheme 11 ATHase-catalyzed regeneration of $\mathrm{NAD}^{+}$and application in cascades with a monooxygenase.

\section{Outlook}

In this account, we have summarized our efforts in the field of ArMs based on the biotin-streptavidin technology. Although several other strategies have been pursued, ${ }^{52,53}$ the versatility of streptavidin to consistently afford very good catalytic performances is nearly unrivaled. We hypothesize that this may be traced back to the commensurate size and topology of the biotin-binding vestibule to accomodate biotinylated organometallic cofactors and their respective substrates. This versatility comes at a price however. Indeed, the biotinylated cofactors remain partially exposed to the solvent upon embedding within streptavidin. As a result, the influence of the protein on the catalytic performance remains 
limited: to date, a ten- to a hundred fold improvement in reaction rate could be achieved. The resulting catalytic performance thus remains well below those of natural enzymes. To overcome this challenge, computational active-site redesign should be combined with high-throughput screening or selection schemes. With this long-term goal in mind, we have identified and addressed many of the challenges. These are summarized in this account: the in vivo directed evolution of artificial metalloenzymes based on the biotin-streptavidin technology thus seems within reach.

Biographical Information

Thomas R. Ward obtained his undergraduate education at the University of Fribourg (Switzerland). Following his PhD in chemistry at the ETHZ in 1991, he joined Roald Hoffmann for an enlightening excursion in applied theoretical chemistry. After a second postdoc with Prof. C. Floriani (University of Lausanne), he obtained a Werner fellowship to initiate his independent carreer at the University of Berne. In 2000, he moved to the University of Neuchâtel and began working on artificial metalloenzyme. He moved to the University of Basel in 2008 and was recently awarded an ERC advanced grant to work on the directed evolution of artificial metalloenzymes in vivo.

Tillmann Heinisch received his $\mathrm{PhD}$ in Chemistry and Protein Crystallography at the University of Basel under Prof. T. R. Ward and T. Schirmer. After joining the group of Prof. Frances Arnold at Caltech for postdoctoral research, he returned to Basel for a second postdoc. His research interest is the structure-based engineering of artificial metalloenzymes.

References

(1) Hyster, T. K.; Arnold, F. H. P450 BM3-Axial Mutations: A Gateway to Non-Natural Reactivity. Isr. J. Chem. 2015, 55, 14-20.

(2) Tyagi, V.; Fasan, R. Myoglobin-Catalyzed Olefination of Aldehydes. Angew. Chem. Int. Ed. 2016, $55,2512-2516$.

(3) Gally, C.; Nestl, B. M.; Hauer, B. Engineering Rieske Non-Heme Iron Oxygenases for the Asymmetric Dihydroxylation of Alkenes. Angew. Chem. Int. Ed. 2015, 54, 12952-12956.

(4) Matthews, M. L.; Chang, W.; Layne, A. P.; Miles, L. A.; Krebs, C.; Bollinger, J. M. Direct Nitration and Azidation of Aliphatic Carbons by an Iron-Dependent Halogenase. Nat. Chem. Biol. 2014, 10, 209-215.

(5) Tebo, A. G.; Pecoraro, V. L. Artificial Metalloenzymes Derived from Three-Helix Bundles. Curr. Opin. Chem. Biol. 2015, 25, 65-70.

(6) Korendovych, I. V; DeGrado, W. F. Catalytic Efficiency of Designed Catalytic Proteins. Curr. Opin. Struct. Biol. 2014, 27, 113-121.

(7) Song, W. J.; Tezcan, F. A. A Designed Supramolecular Protein Assembly with in Vivo Enzymatic Activity. Science. 2014, 346, 1525-1528.

(8) Khare, S. D.; Kipnis, Y.; Greisen, P.; Takeuchi, R.; Ashani, Y.; Goldsmith, M.; Song, Y.; Gallaher, J. L.; Silman, I.; Leader, H.; Sussman, J. L.; Stoddard, B. L.; Tawfik, D. S.; Baker, D. Computational Redesign of a Mononuclear Zinc Metalloenzyme for Organophosphate Hydrolysis. Nat. Chem. Biol. 2012, 8, 294-300. 
(9) Hayashi, T.; Sano, Y.; Onoda, A. Generation of new Artificial Metalloproteins by Cofactor Modification of Native Hemoproteins. Isr. J. Chem. 2015, 55, 76-84.

(10) Ward, T. R. Artificial Metalloenzymes Based on the Biotin-Avidin Technology: Enantioselective Catalysis and Beyond. Acc. Chem. Res. 2011, 44, 47-57.

(11) Maity, B.; Fujita, K.; Ueno, T. Use of the Confined Spaces of Apo-Ferritin and Virus Capsids as Nanoreactors for Catalytic Reactions. Curr. Opin. Chem. Biol. 2015, 25, 88-97.

(12) Lu, Y.; Yeung, N.; Sieracki, N.; Marshall, N. M. Design of Functional Metalloproteins. Nature 2009, 460, 855-862.

(13) Caserta, G.; Roy, S.; Atta, M.; Artero, V.; Fontecave, M. Artificial Hydrogenases: Biohybrid and Supramolecular Systems for Catalytic Hydrogen Production or Uptake. Curr. Opin. Chem. Biol. 2015, 25, 36-47.

(14) Sauer, D. F.; Himiyama, T.; Tachikawa, K.; Fukumoto, K.; Onoda, A.; Mizohata, E.; Inoue, T.; Bocola, M.; Schwaneberg, U.; Hayashi, T.; Okuda, J. A Highly Active Biohybrid Catalyst for Olefin Metathesis in Water: Impact of a Hydrophobic Cavity in a $\beta$-Barrel Protein. ACS Catal. 2015, 5, 7519-7522.

(15) Srivastava, P.; Yang, H.; Ellis-Guardiola, K.; Lewis, J. C. Engineering a Dirhodium Artificial Metalloenzyme for Selective Olefin Cyclopropanation. Nat. Comm. 2015, 6, 7789-7797.

(16) Reetz, M. T. Directed Evolution of Stereoselective Hybrid Catalysts. Top. Organomet. Chem. 2009, 25, 63-92.

(17) Wilson, M. E.; Whitesides, G. M. Conversion of a Protein to a Homogeneous Asymmetric Hydrogenation Catalyst by Site-Specific Modification with a Diphosphine Rhodium(I) Moiety. J. Am. Chem. Soc. 1978, 100, 306-307.

(18) Lin, C.-C.; Lin, C.-C.; Chan, A. S. C. Catalytic Hydrogenation of Itaconic Acid in a Biotinylated Pyrphos-Rhodium(I) System in a Protein Cavity. Tetrahedron: Asymmetry 1999, 10, 1887-1893.

(19) Collot, J.; Gradinaru, J.; Humbert, N.; Skander, M.; Zocchi, A.; Ward, T. R. Artificial Metalloenzymes for Enantioselective Catalysis Based on Biotin-Avidin. J. Am. Chem. Soc. 2003, 125, 9030-9031.

(20) Reetz, M. T.; Peyralans, J. J.-P.; Maichele, A.; Fu, Y.; Maywald, M. Directed Evolution of Hybrid Enzymes: Evolving Enantioselectivity of an Achiral Rh-Complex Anchored to a Protein. Chem. Commun. 2006, 4318-4320.

(21) Skander, M.; Humbert, N.; Gradinaru, J.; Loosli, A.; Zocchi, A.; Ward, T. R. Artificial Metalloenzymes: (Strept)avidin as Host for Enantioselective Hydrogenation by Achiral Biotinylated Rhodium-Diphosphine Complexes. J. Am. Chem. Soc. 2004, 126, 14411-14418.

(22) Klein, G.; Humbert, N.; Gradinaru, J.; Ivanova, A.; Gilardoni, F.; Rusbandi, U. E.; Ward, T. R. Tailoring the Active Site of Chemzymes by using a Chemogenetic-Optimization Procedure: Towards Substrate-Specific Artificial Hydrogenases Based on the Biotin-Avidin Technology. Angew. Chem. Int. Ed. 2005, 44, 7764-7767. 
(23) Pierron, J.; Malan, C.; Creus, M.; Gradinaru, J.; Hafner, I.; Ivanova, A.; Sardo, A.; Ward, T. R. Artificial Metalloenzymes for Asymmetric Allylic Alkylation on the Basis of the Biotin-Avidin Technology. Angew. Chem. Int. Ed. 2008, 47, 701-705.

(24) Köhler, V.; Mao, J.; Heinisch, T.; Pordea, A.; Sardo, A.; Wilson, Y. M.; Knörr, L.; Creus, M.; Prost, J.-C.; Schirmer, T.; Ward, T. R. OsO4-Streptavidin: a Tunable Hybrid Catalyst for the Enantioselective cis-Dihydroxylation of Olefins. Angew. Chem. Int. Ed. 2011, 50, $10863-$ 10866.

(25) Pordea, A.; Creus, M.; Panek, J.; Duboc, C.; Mathis, D.; Novic, M.; Ward, T. R. Artificial Metalloenzyme for Enantioselective Sulfoxidation Based on Vanadyl-Loaded Streptavidin. $J$. Am. Chem. Soc. 2008, 130, 8085-8088.

(26) Thomas, C. M.; Letondor, C.; Humbert, N.; Ward, T. R. Aqueous Oxidation of Alcohols Catalyzed by Artificial Metalloenzymes Based on the Biotin-Avidin Technology. $J$. Organomet. Chem. 2005, 690, 4488-4491.

(27) Letondor, C.; Humbert, N.; Ward, T. R. Artificial Metalloenzymes Based on Biotin-Avidin Technology for the Enantioselective Reduction of Ketones by Transfer Hydrogenation. Proc. Natl. Acad. Sci. 2005, 102, 4683-4687.

(28) Creus, M.; Pordea, A.; Rossel, T.; Sardo, A.; Letondor, C.; Ivanova, A.; Letrong, I.; Stenkamp, R. E.; Ward, T. R. X-ray Structure and Designed Evolution of an Artificial Transfer Hydrogenase. Angew. Chem. Int. Ed. 2008, 47, 1400-1404.

(29) Heinisch, T.; Langowska, K.; Tanner, P.; Reymond, J.-L.; Meier, W.; Palivan, C.; Ward, T. R. Fluorescence-Based Assay for the Optimization of the Activity of Artificial Transfer Hydrogenase within a Biocompatible Compartment. ChemCatChem 2013, 5, 720-723.

(30) Dürrenberger, M.; Heinisch, T.; Wilson, Y. M.; Rossel, T.; Nogueira, E.; Knörr, L.; Mutschler, A.; Kersten, K.; Zimbron, M. J.; Pierron, J.; Schirmer, T.; Ward, T. R. Artificial Transfer Hydrogenases for the Enantioselective Reduction of Cyclic Imines. Angew. Chem. Int. Ed. 2011, 50, 3026-3029.

(31) Köhler, V.; Wilson, Y. M.; Dürrenberger, M.; Ghislieri, D.; Churakova, E.; Quinto, T.; Knörr, L.; Häussinger, D.; Hollmann, F.; Turner, N. J.; Ward, T. R. Synthetic Cascades are Enabled by Combining Biocatalysts with Artificial Metalloenzymes. Nat. Chem. 2013, 5, 93-99.

(32) Quinto, T.; Schwizer, F.; Zimbron, J. M.; Morina, A.; Köhler, V.; Ward, T. R. Expanding the Chemical Diversity in Artificial Imine Reductases Based on the Biotin-Streptavidin Technology. ChemCatChem 2014, 6, 1010-1014.

(33) Schwizer, F.; Köhler, V.; Dürrenberger, M.; Knörr, L.; Ward, T. R. Genetic Optimization of the Catalytic Efficiency of Artificial Imine Reductases Based on Biotin-Streptavidin Technology. ACS Catal. 2013, 3, 1752-1755.

(34) Wilson, Y. M.; Dürrenberger, M.; Nogueira, E. S.; Ward, T. R. Neutralizing the Detrimental Effect of Glutathione on Precious Metal Catalysts. J. Am. Chem. Soc. 2014, 136, 8928-8932.

(35) Zimbron, J. M.; Heinisch, T.; Schmid, M.; Hamels, D.; Nogueira, E. S.; Schirmer, T.; Ward, T. R. A Dual Anchoring Strategy for the Localization and Activation of Artificial Metalloenzymes Based on the Biotin-Streptavidin Technology. J. Am. Chem. Soc. 2013, 135, 5384-5388. 
(36) Munoz Robles, V.; Dürrenberger, M.; Heinisch, T.; Lledós, A.; Schirmer, T.; Ward, T. R.; Maréchal, J.-D. Structural, Kinetic, and Docking Studies of Artificial Imine Reductases Based on Biotin-Streptavidin Technology: An Induced Lock-and-Key Hypothesis. J. Am. Chem. Soc. 2014, 136, 15676-15683.

(37) Chatterjee, A.; Mallin, H.; Klehr, J.; Vallapurackal, J.; Finke, A.; Vera, L.; Marsh, M.; Ward, T. R. An Enantioselective Artificial Suzukiase Based on the Biotin-Streptavidin Technology. Chem. Sci. 2015, 7, 673-677.

(38) Hyster, T. K.; Knörr, L.; Ward, T. R.; Rovis, T. Biotinylated Rh(III) Complexes in Engineered Streptavidin for Accelerated Asymmetric C-H Activation. Science. 2012, 338, 500-503.

(39) Lo, C.; Ringenberg, M. R.; Gnandt, D.; Wilson, Y.; Ward, T. R. Artificial Metalloenzymes for Olefin Metathesis Based on the Biotin-(Strept)avidin Technology. Chem. Commun. 2011, 47, 12065-12067.

(40) Kajetanowicz, A.; Chatterjee, A.; Reuter, R.; Ward, T. R. Biotinylated Metathesis Catalysts: Synthesis and Performance in Ring Closing Metathesis. Catal. Lett. 2013, 144, 373-379.

(41) Noyori, N.; Hashigushi, S. Asymmetric Transfer Hydrogenation Catalyzed by Chiral Ruthenium Complexes. Acc. Chem. Res. 1997, 30, 97-102.

(42) Mitsukura, K.; Suzuki, M.; Shinoda, S.; Kuramoto, T.; Yoshida, T.; Nagasawa, T. Purification and Characterization of a Novel (R)-Imine Reductase from Streptomyces sp. GF3587. Biosci. Biotechnol. Biochem. 2011, 75, 1778-1782.

(43) Watanabe, M.; Murata, K.; Ikariya, T. Enantioselective Michael Reaction Catalyzed by WellDefined Chiral Ru Amido Complexes: Isolation and Characterization of the Catalyst Intermediate, Ru Malonato Complex having a Metal-Carbon Bond. J. Am. Chem. Soc. 2003, $125,7508-7509$.

(44) Palivan, C. G.; Goers, R.; Najer, A.; Zhang, X.; Car, A.; Meier, W. Bioinspired Polymer Vesicles and Membranes for Biological and Medical Applications. Chem. Soc. Rev. 2016, 45, 377-411.

(45) Sletten, E. M.; Bertozzi, C. R. Bioorthogonal Chemistry: Fishing for Selectivity in a Sea of Functionality. Angew. Chem. Int. Ed. 2009, 48, 6974-6998.

(46) Burtscher, D.; Grela, K. Aqueous Olefin Metathesis. Angew. Chem. Int. Ed. 2009, 48, 442-454.

(47) Mallin, H.; Hestericová, M.; Reuter, R.; Ward, T. R. Library Design and Screening Protocol for Artificial Metalloenzymes Based on the Biotin-Streptavidin Technology. Nat. Protoc. 2016, $11,835-852$.

(48) Uozumi, Y.; Matsuura, Y.; Arakawa, T.; Yamada, Y. M. a. Asymmetric Suzuki-Miyaura Coupling in Water with a Chiral Palladium Catalyst Supported on an Amphiphilic Resin. Angew. Chem. Int. Ed. 2009, 48, 2708-2710.

(49) Trost, B. M.; Frederiksen, M. U.; Rudd, M. T. Ruthenium-Catalyzed Reactions - A Treasure Trove of Atom-Economic Transformations. Angew. Chem. Int. Ed. 2005, 44, 6630-6666.

(50) Völker, T.; Dempwolff, F.; Graumann, P. L.; Meggers, E. Progress Towards Bioorthogonal Catalysis with Organometallic Compounds. Angew. Chem. Int. Ed. 2014, 53, 10536-10540. 
(51) Satoh, T.; Miura, M. Oxidative Coupling of Aromatic Substrates with Alkynes and Alkenes under Rhodium Catalysis. Chem. Eur. J. 2010, 16, 11212-11222.

(52) Yu, F.; Cangelosi, V. M.; Zastrow, M. L.; Tegoni, M.; Plegaria, J. S.; Tebo, A. G.; Mocny, C. S.; Ruckthong, L.; Qayyum, H.; Pecoraro, V. L. Protein Design: Toward Functional Metalloenzymes. Chem. Rev. 2014, 114, 3495-3578.

(53) Lewis, J. C. Artificial Metalloenzmyes and Metallopeptide Catalysts for Organic Synthesis. ACS Catal. 2013, 3, 2954-2975.

(54) Fahey, R. C.; Brown, W. C.; Adams, W. B.; Worsham, M. B. Occurrence of Glutathione in Bacteria. J. Bacteriol. 1978, 133, 1126-1129.

(55) Wörsdörfer, B.; Woycechowsky, K. J.; Hilvert, D. Directed Evolution of a Protein Container. Science. 2011, 331, 589-592.

(56) Engström, K.; Johnston, E. V.; Verho, O.; Gustafson, K. P. J.; Shakeri, M.; Tai, C. W.; Bäckvall, J. E. Co-Immobilization of an Enzyme and a Metal into the Compartments of Mesoporous Silica for Cooperative Tandem Catalysis: An Artificial Metalloenzyme. Angew. Chem. Int. Ed. 2013, 52, 14006-14010.

(57) Rowles, I.; Malone, K. J.; Etchells, L. L.; Willies, S. C.; Turner, N. J. Directed Evolution of the Enzyme Monoamine Axidase (MAO-N): Highly Efficient Chemo-Enzymatic Deracemisation of the Alkaloid (+/-)-Crispine A. ChemCatChem 2012, 4, 1259-1261.

(58) Hall, M.; Bommarius, A. S. Enantioenriched Compounds via Enzyme-Catalyzed Redox Reactions. Chem. Rev. 2011, 111, 4088-4110.

(59) Quinto, T.; Köhler, V.; Ward, T. R. Recent Trends in Biomimetic NADH Regeneration. Top. Catal. 2013, 57, 321-331.

(60) Okamoto, Y.; Köhler, V.; Paul, C. E.; Hollmann, F.; Ward, T. R. Efficient In Situ Regeneration of NADH Mimics by an Artificial Metalloenzyme. ACS Catal. 2016, 6, 3553-3557. 


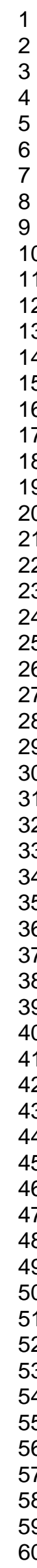

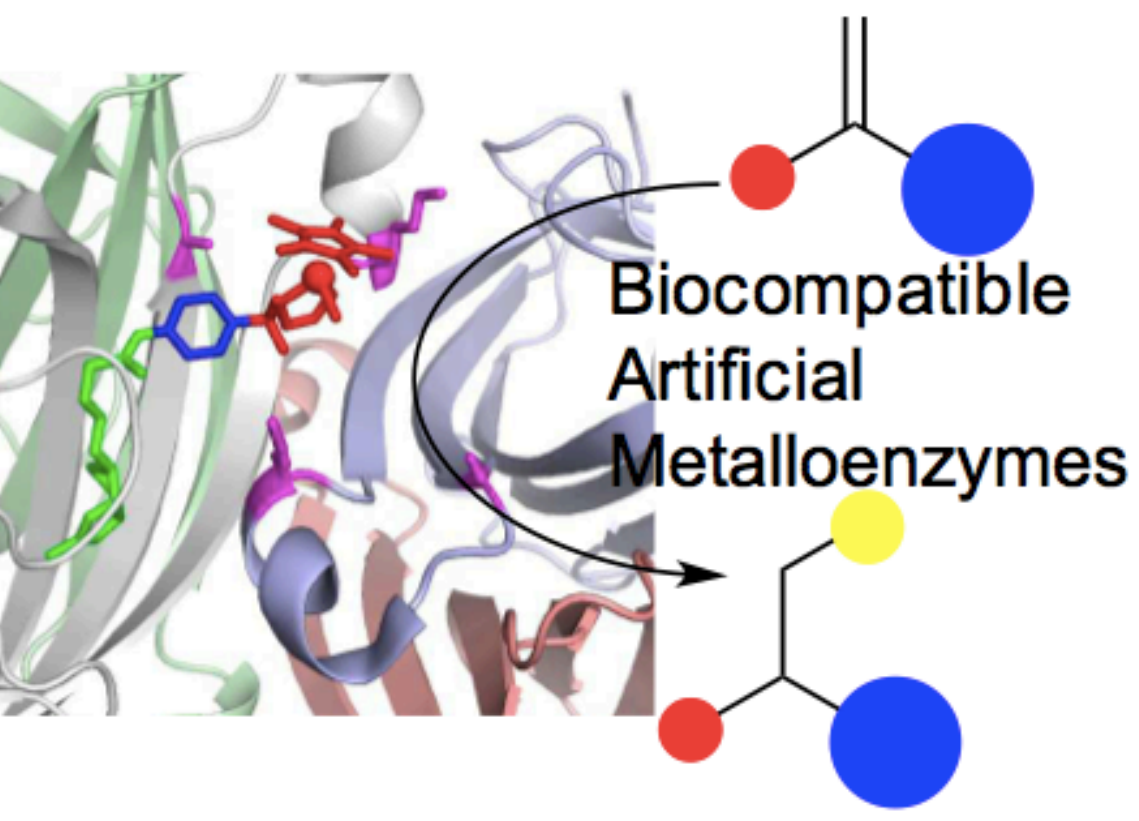

Imine reduction metathesis C-H activation enzyme cascades catalysis in cell lysates 